\title{
Las noticias impresas en la Monarquía Hispánica (siglos XVI-XVIII): nuevos estudios y métodos
}

\section{Printed News in the Hispanic Monarchy (16th to 18th cent.): New Studies and Methods}

Paul Firbas ${ }^{1}$ y Jesús Jiménez Valdés ${ }^{2}$

Participantes: Francisco Baena Sánchez (Univ. de Sevilla), Javier Díaz-Noci (Univ. Pompeu Fabra), Carmen Espejo Cala (Univ. de Sevilla), Paul Firbas (Stony Brook Univ.), Pedro Guibovich Pérez (Pontificia Univ. Católica del Perú), María Gracia Ríos Taboada (Pontificia Univ. Católica del Perú), José A. Rodríguez Garrido (Pontificia Univ. Católica del Perú) y Tadeo Valverde Molina (Univ. de Salamanca)

\section{Resumen}

Este trabajo presenta la conversación editada del simposio "Efímero: impresos noticiosos de la modernidad temprana en el mundo hispánico", realizado virtualmente en Stony Brook University en marzo de 2021, con especialistas de universidades americanas y europeas. Se exponen nuevas líneas de investigación, métodos, bibliografía y proyectos sobre no-

1 Profesor asociado en el departamento de Hispanic Languages and Literature de Stony Brook University (New York). Correspondencia (Corresponding author): paul.firbas@stonybrook.edu

Código ORCID: 0000-0003-3977-2449

2 Estudiante doctoral en el departamento de Hispanic Languages and Literature de Stony Brook University (New York).

Email: jesus.jimenezvaldes@stonybrook.edu 
Las noticias impresas en la Monarquía Hispánica (siglos XVI-XVIII): nuevos estudios y métodos

ticias impresas de los siglos XVI al XVIII, con énfasis en la circulación transatlántica entre España y el Perú. Específicamente, se discuten las redes de noticias, el mercado y taller editorial en Lima (1700-1711), los grabados y los sueltos teatrales vinculados a relaciones de sucesos, la censura, y la circulación de los impresos efímeros.

Palabras clave: historia de la imprenta, periodismo temprano, Espańa siglos XVI-XVIII, Lima colonial, Perú.

\section{Abstract}

This work presents the edited conversation of the symposium "Efímero: Early Modern News-Sheets and Pamphlets in the Hispanic World," held virtually at Stony Brook University in March 2021 with specialists from Europe and the Americas. The text presents new research, methods, bibliography, and projects on sixteenth to eighteenth century printed news, with focus on the transatlantic circulation between Spain and Peru. Specifically, it discusses news networks, the editorial market in Lima (1700-1711), engravings and theater pamphlets related to relaciones de sucesos, censorship, and the circulation of ephemera.

Keywords: printing press history, early journalism, Early Modern Spain, colonial Lima.

\section{Introducción: una conversación efímera}

En marzo de 2021 organizamos en Stony Brook University un simposio virtual sobre los impresos de noticias, pliegos sueltos y textos efímeros de la Monarquía Hispánica entre los siglos XVI y XVIII, bajo el título "Efímero: Early Modern News-Sheets and Pamphlets in the Hispanic World". Se trataba de reunirnos para discutir los avances y problemas com- 
partidos en nuestras investigaciones sobre un corpus muy heterogéneo de impresos, intentando conectar las redes de noticias europeas con las hispanoamericanas, especialmente con el virreinato del Perú y su imprenta en Lima. El formato del simposio fue el de una conversación o mesa redonda académica, siguiendo un guion básico de cinco bloques temáticos, en los cuales los participantes intervinieron según sus áreas específicas de investigación. ${ }^{3}$

El simposio contó con la participación de ocho colegas de universidades de América y Europa. ${ }^{4}$ La conversación, de dos horas, se grabó en video y fue luego transcrita y editada por Paul Firbas y Jesús Jiménez. El texto editado ha sido revisado por todos los participantes del simposio para la preparación de esta versión final.

\section{Nuevas perspectivas en los estudios de los impresos de noticias}

Paul Firbas: Nuestro primer bloque temático es una invitación a pensar los cambios que hemos vivido en las últimas

3 La organización del simposio formó parte del proyecto de investigación "News Production and Networks in Colonial Lima (1620-1720): the Contreras Family Print Shop", dirigido por Paul Firbas, que contó con el apoyo de una beca del Humanities Institute at Stony Brook University (Faculty Fellowship, spring 2021). Además, el simposio y esta publicación participan del proyecto "Circulación imperial y memoria de la ciudad: Diario de noticias sobresalientes en Lima" (ID 709) de la Pontificia Universidad Católica del Perú, a cargo del Grupo de Investigación y Edición de Textos Coloniales Hispanoamericanos (GRIETCOH). La página web del simposio (you.stonybrook.edu/efimero) contiene información académica sobre los participantes, material complementario (diapositivas y video) y enlaces a las diferentes instituciones que colaboraron con este proyecto, a las que expresamos nuestro agradecimiento.

4 La conversación estuvo abierta al público y tuvimos la suerte de contar con los comentarios de Marina Garone (UNAM) y Judith Farré (CSIC), que hemos incluido también en esta versión final. 
Las noticias impresas en la Monarquía Hispánica (siglos XVI-XVIII): nuevos estudios y métodos

décadas -en los últimos 25 a 30 años- en los estudios del área hispánica, no solo sobre la historia del libro y la imprenta, sino específicamente sobre los pliegos sueltos y la producción y circulación de noticias. Para empezar, querría invitarlos a compartir sus impresiones sobre estos cambios y poder así armar un relato para saber qué ha pasado y qué direcciones podrían tomar los estudios en el campo de la producción y circulación de noticias impresas, relaciones de sucesos y, en general, sobre los textos efímeros de la modernidad temprana.

Carmen Espejo: En los últimos años he estado trabajando de manera muy intensa, con toda modestia, en el concepto de "redes de noticias" (news networks) y, de acuerdo con lo que he leído en los últimos tiempos, este concepto, etiqueta o marbete ha tenido éxito. 5 De hecho, se asume por parte de los investigadores del periodismo de la Edad Moderna. Ha llegado incluso a los manuales universitarios, a los libros de texto, a las colecciones más generales. También se ha avanzado bastante en la cartografía o la radiografía de cómo eran esas redes y cómo funcionaban en la práctica, vinculando todos los territorios de Europa, pero llegando mucho más allá. Seguramente algunos compañeros aquí presentes podrán precisar mucho más hasta qué punto se han radiografiado esas redes. Mi percepción, una percepción no crítica, pero que pretende introducir un elemento que permita seguir avanzando, es que, una vez que hemos definido el concepto y la cartografía parece que hemos llegado a un callejón sin salida: ¿ahora qué hacemos con el concepto? Para mí, una de las lecturas más relevantes de los últimos meses, ha sido una de un artículo de Filippo de Vivo, donde dice que ahora deberíamos empezar a hacer la microhistoria de las redes paneuropeas de comunicación o de las redes mundiales de comunicación de noticias. ${ }^{6}$ Parece una contradicción, porque si nuestra perspectiva era paneuropea

5 Ver Carmen Espejo Cala (2012).

6 Ver Filippo de Vivo (2019). 
primero, globalizada después, ¿por qué ahora vamos a hacer microhistoria? Según Filippo de Vivo, es la única manera que tenemos de lograr que el relato sea tridimensional, de que podamos descubrir quiénes eran los agentes que intervenían en la comunicación y para qué se utilizaban las redes. Su propio trabajo es un estudio de una red muy concreta que desde el Mediterráneo y Venecia pasa por varios lugares y llega incluso a Oriente Medio. Es una red cuyos agentes y motivaciones también son muy concretos. Él propone que, sumando esos enfoques micro-históricos, le demos tres dimensiones y más densidad al concepto que, como digo, había surgido con mucho éxito pero no había conseguido avanzar más.

Paul Firbas: Por otro lado, en algunos estudios sobre "redes" se usan conceptos de las ciencias duras y se aplican herramientas de Inteligencia Artificial. En lo personal, cuando leo artículos que exploran el movimiento o "difusión" de la información en disciplinas que tradicionalmente no están próximas a las humanidades, siento que me beneficiaría mucho de trabajar más en equipo. Es evidente que el campo de las humanidades también se ha transformado.

Javier Díaz-Noci: Hay una peculiaridad europea y española, ya que estamos en un diálogo más allá de las fronteras intercontinentales, y es que los estudios sobre noticias en el período moderno, publicaciones periódicas y pre-periódicas, están entre las humanidades y las ciencias sociales. También por razones institucionales, porque buena parte de nosotros trabajamos en facultades de Ciencias de la Información y de la Comunicación. A nosotros nos evalúan desde la perspectiva de las Ciencias Sociales, por eso hemos incorporado algunas de sus técnicas y métodos. Concretamente, lo que estamos intentando hacer es pasar del facsímil, o de una mera transcripción, que es lo que hemos intentado hacer con la Gaceta 
Las noticias impresas en la Monarquía Hispánica (siglos XVI-XVIII): nuevos estudios y métodos

de Roma, al machine readable-text, a la ontología ${ }^{7}$ y marcaje XML. En esa edición de la Gaceta de Roma, ${ }^{8}$ accesible a través de Internet, utilizamos bases de datos para análisis de contenido a partir de categorías como el análisis social de redes (social network analysis). No somos los únicos que trabajamos en esta línea, desde luego. Desde el campo de las humanidades, se ha utilizado en Espańa para discernir cuál era la red de dramaturgos del Siglo de Oro. Así, de la mano de Carmen Espejo nos hemos asociado con redes de investigación europeas y hemos abrazado el concepto de news network. Una perspectiva que va mucho más allá de lo nacional. Esto a los españoles nos ha venido muy bien, por razones internas y externas. Internas porque lo que hoy llamamos Espańa, en la Edad Moderna estaba compuesta por numerosos reinos con más o menos autonomía (algunos, como el caso de Cataluña, habían pasado a estar brevemente incluso bajo dominio francés). Además, se produjeron en diversas lenguas y los impresos en castellano se publicaron más allá de sus fronteras, sin ir más lejos, en Ámsterdam y el Flandes español, así como en las posesiones españolas americanas. Finalmente, abrazamos una perspectiva que me interesa, que no es nueva, porque viene de la Inglaterra de los ańos 60 y 70, que es la perspectiva de la historia social en la que básicamente, más que una historia de instituciones y empresas, de grandes títulos de prensa, intentamos hacer una historia de redes y de las personas que estaban detrás. Esto no es fácil, muchas veces carecemos de imágenes y no podemos ponerles caras a muchos de los artífices. A veces, tampoco nombres. Nos movemos con nombres de gestores o editores pero no de periodistas, que con certeza existían, por ejemplo en gacetas de Bruselas de finales del XVII. A mí me interesa personalmente la ima-

7 El concepto de ontología se refiere aquí a categorías semánticas jerarquizadas que luego se aplican en procedimientos de inteligencia artificial o machine learning para el estudio de los textos.

8 Rafael Soto Escobar, Javier Díaz-Noci y Carmen Espejo Cala (2020). 
gen del periodista, porque ya había literatura de ficción que trata al periodista (gacetero en ese momento) como objeto de chanza, y porque la gaceta se estaba constituyendo no como un género noticioso sino literario: la gaceta burlesca, cuyo origen podemos situar en Francia e Italia, antes de la Guerra de los Treinta Años. Aquí hay un inmenso material no solo por explorar sino también por interpretar, y unas cuántas perspectivas teóricas y metodológicas para aplicar. ${ }^{9}$

Paul Firbas: Hemos progresado enormemente en los últimos veinte años en el acopio de la información. Ahora podemos acceder a un corpus que antes era impensable, pero no lo estamos leyendo humanamente -sería una tarea muy grande-, y esto produce otro tipo de sentidos. Por otro lado, la circulación de las noticias y su lectura -dentro de la historia social y la teoría de la recepción- es un fenómeno de difícil acceso y estudio. En el caso europeo quizás haya más información, pero sobre el contexto hispanoamericano sabemos muy poco sobre quién realmente vendía noticias, en qué contexto se vendían y cómo y dónde circulaban. Yo tengo dudas muy fuertes sobre la naturaleza comercial de estos impresos efímeros virreinales durante la Guerra de Sucesión. A partir de 1723, sí que encuentro impresos limeños que dicen: "Véndese en la imprenta nueva". Creo que deben entenderse dentro de una esfera más amplia de favores y clientelismo. Necesitamos más estudios sobre la historia del correo y de la circulación postal, que deberían conectarse con la historia de la imprenta; y sobre los agentes de distribución y venta.

Javier Díaz-Noci: Sobre esto, Carmen Espejo, Francisco Baena y yo tenemos un par de artículos en los que comparamos los intercambios de noticias entre los diferentes editores de las principales ciudades españolas de la Edad Moderna. ${ }^{10}$

9 Ver Giulio Cesare Croce y Javier Díaz-Noci (2021).

10 Javier Díaz-Noci, Carmen Espejo y Francisco Baena (2018). 
Las noticias impresas en la Monarquía Hispánica (siglos XVI-XVIII): nuevos estudios y métodos

Sevilla, por supuesto, claramente, la más poblada, Madrid, en menor medida, Barcelona, Zaragoza -que ha sido muy olvidada-, San Sebastián, que era el puerto de entrada del correo postal de Centroeuropa y arrastraba noticias de Flandes, de lo que hoy es Alemania e incluso de Dinamarca. Con certeza, esto se vendía. Hay un caso particular, que yo no he investigado en profundidad - del que hay escritas algunas tesis- sobre una pugna dentro del gremio de impresores, muy dividido, del reino de Aragón (Cataluña, Valencia, Baleares y el propio Aragón). En 1706, durante la Guerra de Sucesión, el archiduque Carlos de Austria comienza a dar monopolios. Concede uno en Barcelona a Rafael de Figueró. ${ }^{11}$ Carmen y Francisco tienen mucha información sobre Sevilla, que es un caso muy importante y también muy temprano.

Francisco Baena: Quisiera señalar dos líneas o direcciones que puede estar tomando nuestro campo de conocimiento. Una que se ha mencionado, directa o indirectamente, es la de las humanidades digitales, por ejemplo, en la línea de la digitalización de relaciones y gacetas, de la web semántica, ontologías, la representación mediante mapas de las redes de noticias, la codificación de los textos mediante lenguajes XML, etc. ${ }^{12} \mathrm{Y}$ la otra, que quizás entronca con uno de los últimos trabajos que hemos realizado Carmen y yo, próximo a ser publicado, es una que se ha abordado menos y que tiene que ver con el formato. Todos somos conscientes de que nuestro conocimiento sobre el periodismo de la Edad Moderna ha experimentado un desarrollo notable en las últimas décadas. Sin embargo, esas investigaciones se han centrado mucho en el contenido, en el

11 Ver el libro de Xevi Camprubí sobre este impresor (2018), basado en su tesis doctoral de 2014.

12 Un primer estudio computacional desde la ontología para los impresos noticiosos españoles, que planteaba clasificaciones de las noticias y tipología de sus formas impresas, puede verse en Francisco Baena Sánchez y Carmen Espejo Cala (2017). 
mensaje o, incluso, desde el punto de vista del contexto de la información, en los autores materiales o intelectuales de los textos informativos. Así que quizás sería importante ampliar nuestro punto de vista, pasando a investigar sobre la forma o formato de estos impresos informativos, sobre el diseño, las imágenes o el estilo del discurso. En este segundo caso, creo que la bibliografía no es tan amplia. Creo que ahí puede haber un campo que sería muy interesante desarrollar.

María Gracia Ríos Taboada: Desde mi tesis doctoral me he enfocado en la piratería a fines del XVI, sobre todo concentrada en la figura de Francis Drake. Me interesaba estudiar cómo la piratería era representada en las relaciones de sucesos, pero ahora me interesa centrarme más en lo que la piratería nos puede decir sobre esas relaciones, sobre noticias extraordinarias, gacetas, etc., y sobre la historia de la imprenta y del periodismo. Hay muchísimo material y mucho por hacer, en realidad. Estoy en dos proyectos particulares. Uno de ellos es el de la primera noticia que se imprime en Lima, que trata sobre la captura de un pirata. Es un texto muy interesante. Es una relación que manda hacer el virrey al correo mayor, y se imprime en el taller de Antonio Ricardo en 1596, que es el primer impresor de Lima. Y luego, siguiendo la serie de noticias que corresponde al momento de la Guerra de Sucesión en el primer periódico de Lima, ${ }^{13}$ es interesante ver cómo la piratería aparece en momentos clave de la historia del periodismo temprano del virreinato. La piratería también nos permite saber más sobre la producción impresa de textos, por qué y qué se publicaba en un momento dado. Si se analizan estos textos con detenimiento, hay mucha información anexa, más allá de la historia que cuenta la noticia.

13 Ver el Diario de noticias sobresalientes en Lima y Noticias de Europa (17001711), edición y estudio de Paul Firbas y José A. Rodríguez Garrido (volumen 1, 2017; el volumen 2 está actualmente en prensa). 

y métodos

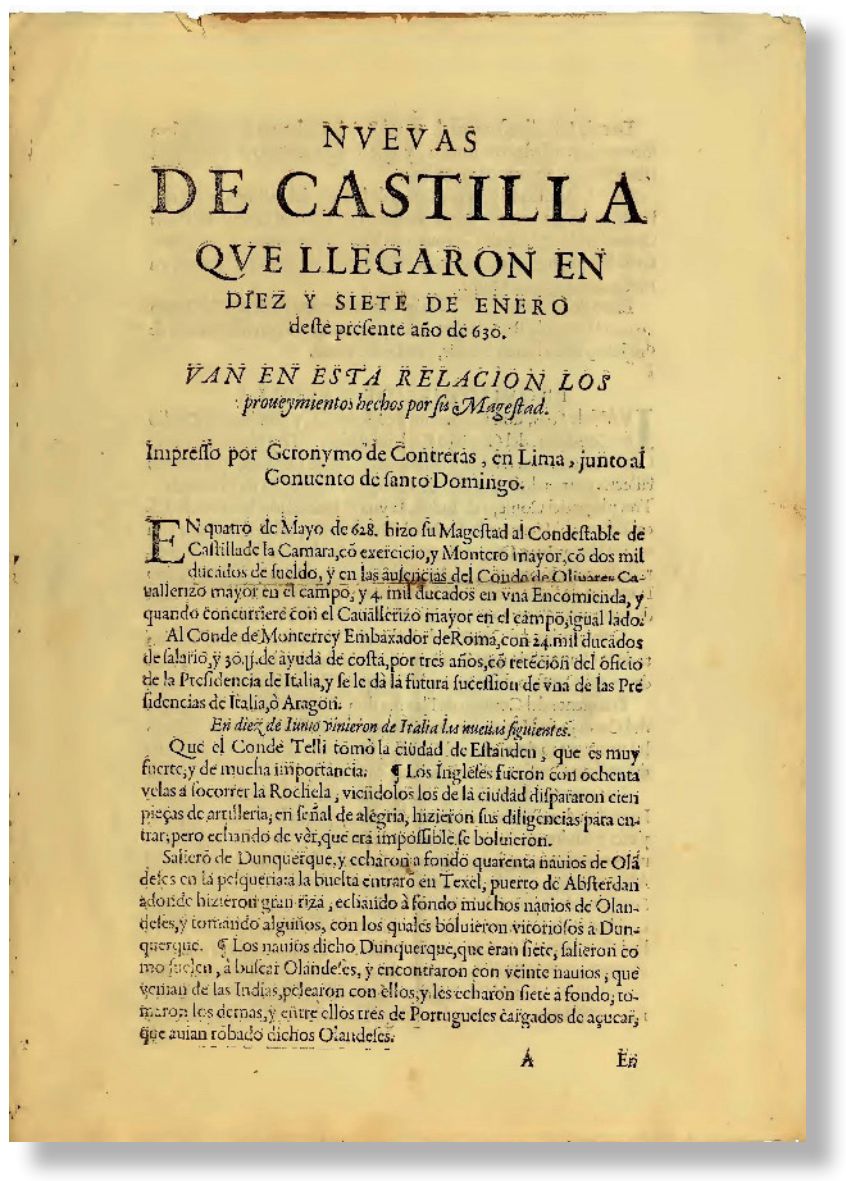

372 Figura 1. Ejemplar de Nuevas de Castilla (Lima, 1630), serie no periódica de noticias que publicaba en Lima el impresor sevillano Jerónimo de Contreras entre 1621 y 1632 . Este impreso (de cuatro páginas) incluye noticias de Italia y una lista de provisiones civiles y eclesiásticas para Castilla, Perú y Nueva España. Sobre estas primeras publicaciones de Jerónimo de Contreras y el desarrollo de una cultura transatlántica de información pública que fue fragmentando la autoridad central de la Corona, ver el reciente estudio de Arthur Weststeijn (2021). [Imagen: cortesía de la Biblioteca John Carter Brown] 


\section{Métodos y casos de estudio}

Paul Firbas: En este bloque vamos a reflexionar sobre métodos y casos de estudio, a partir de nuestros trabajos, y a abstraer ciertas cuestiones metodológicas: los casos específicos, la microhistoria, la casuística, podrían servirnos para extrapolar preguntas metodológicas y prácticas de investigación, o cuestiones más generales, que luego podríamos incorporar en clases y seminarios.

Carmen Espejo: Se me ocurren varias cosas. Hablabas de tu preocupación por saber si se trataba, efectivamente, de productos que se vendían, dimensión que es muy difícil de probar y solemos obviar, como tantas otras que solemos obviar cuando emprendemos estos estudios. Hablabas de la dificultad de llevar a cabo estudios de recepción, desde el planteamiento mismo de si verdaderamente el mercado suponía un intercambio económico de los impresos y, por supuesto, dentro de los estudios de recepción, el problema de a quién llegaban esas noticias impresas, cómo llegaban y por qué. Un apunte en este sentido: recientemente he leído un trabajo de Manuel Suárez Rivera, del Instituto de Investigaciones Bibliográficas de la UNAM, sobre la Gaceta de México (17841785) y me ha dado mucho que pensar. Es un estudio sobre la viabilidad económica de la Gaceta de México. ${ }^{14}$ Él parte de la idea de que difícilmente podemos suponer que estos periódicos obtenían tantos ingresos por venta como para ser autosuficientes. Sabemos que incluso en nuestros días esto supone un reto muy difícil de cumplir para los periódicos actuales, o sea, cómo sería posible imaginar que estas gacetas impresas en América, en concreto, a finales del siglo XVIII, hubieran sido autosuficientes simplemente a partir de sus ingresos en venta. Suárez hace un estudio exhaustivo de todos los números que se conservan, sobre todo en la parte de los

14 Manuel Suárez Rivera (2015). 
Las noticias impresas en la Monarquía Hispánica (siglos XVI-XVIII): nuevos estudios y métodos

anuncios, para llegar a la conclusión -tomando otros documentos secundarios que encuentra en archivos- de que la venta de la gaceta asociada a otros productos de la misma imprenta seguramente sí compensaba el esfuerzo de imprimirla, a sabiendas de que iba a obtener pérdidas económicas. Se trata de un artículo de empresa económica aplicado a la gaceta del siglo XVIII que me pareció muy sugerente, que abre nuevas perspectivas, pues es una pregunta que nos hemos hecho todos. ¿Esto se vendía? ¿Le reportaba un beneficio real a quien lo imprimía? ¿Hasta qué punto podía pagarse esa complicada red que transportaba noticias de un punto a otro si al final lo que se iba a vender iba a tener un coste, sabemos, poco elevado en un contexto de población muy poco alfabetizada?

Paul Firbas: Son todas preguntas muy pertinentes y, además, nos obligan a pensar también en los cambios que se produjeron desde la segunda mitad del siglo XVIII, como, por ejemplo, el manejo centralizado del correo marítimo y el aumento del número de imprentas que operaban en la ciudad virreinal. Pero quiero hacer un brevísimo comentario, que me devuelve a finales del XVII. En uno de los documentos que publicó José Toribio Medina en La imprenta en Lima, sobre los contratos que la familia Contreras gestionaba para renovar el privilegio de imprimir cartillas en el Perú, hay un dato interesante. Aunque la venta exclusiva de cartillas debía beneficiar al hospital de huérfanos de la ciudad, el trabajo de impresión proporcionaba un ingreso importante a los Contreras, por eso el impresor menciona que él servía al Rey en sus despachos "graciosamente y sin interés alguno". ${ }^{15}$ Es como si dijera que con el privilegio de las cartillas, indirectamente, se costeaba la publicación de los despachos oficiales del gobierno virreinal, que, en el caso de Lima entre 1700 a

15 José Toribio Medina (1904, tomo I, p. 456). 
1711, podemos pensar que incluía las noticias impresas. Entonces, sería posible entender que el proyecto de los Diarios y las Noticias de Europa se financiaba, inicialmente, a través de la concesión de esos privilegios. Por eso no creo que la venta de esos impresos haya sido tan relevante en los años de la Guerra de Sucesión, en el contexto virreinal, y dentro de una economía de favores.

Carmen Espejo: Tiene mucho sentido, sí.

Pedro Guibovich Pérez: El comentario de Carmen me parece muy acertado. Es muy difícil determinar si los textos se vendieron, o cuáles eran las condiciones de comercialización, etc. Pero yo creo que sí, porque los impresores eran empresarios, y desde hace tiempo, aunque no lo consigo, quiero ver las cuentas de la Tesorería del virreinato, que se encuentran en el Archivo General de la Nación y los libros de carga y data, que alguna vez revisó el doctor Lohmann Villena, y allí se da cuenta - porque lo registra- el dinero que daba el virrey o la secretaría del virreinato para la impresión de textos. Desafortunadamente, hasta ahora no he podido ir al archivo, pero estoy convencido de que hay información muy rica. Lo digo porque en las cuentas del Tribunal de la Inquisición se registran los gastos de la impresión de libros y de otros textos. En esas cuentas, que felizmente han llegado a nosotros, en el Archivo de la Real Hacienda, tengo la certeza de que vamos a encontrar información muy valiosa.

Paul Firbas: Esperemos que pronto podamos regresar a los archivos. Como bien dices, hay mucho trabajo por hacer en esos libros de cuentas coloniales. Marina Garone, que está en México y se acaba de conectar, quiere también hacer un comentario.

Marina Garone: La referencia de Carmen y Pedro se aplica también a la imprenta en México. Es interesante la perspectiva económica para pensar este asunto, aunque quizás debe- 
Las noticias impresas en la Monarquía Hispánica (siglos XVI-XVIII): nuevos estudios y métodos

ríamos tener cuidado de no caer en anacronismos y pensar que este género editorial, este o cualquier otro en las imprentas coloniales fuera autosuficiente. Tal vez es mejor pensarlo en términos de economía concurrente, porque también tenemos otros indicios, como el tiempo de labor de las prensas y la cuestión de lo asistemático de la periodicidad de las noticias y la cronología de estos documentos, que hace pensar que se publicaban cuando había una determinada cantidad de noticias que enunciar, y cuando tuvieran las prensas paradas en relación con libros o impresos que sí estaban financiados. Creo que eso no tiene que ver solo con cuánto cuesta la venta de las publicaciones, sino de poner unos géneros en diálogo con otros, es decir, ver la cronología de estas publicaciones en relación con la producción de una imprenta para saber la posibilidad que tenía un taller de sacar los periódicos. Por otro lado, pienso también que se señala un punto muy relevante: en México, al menos, estos son géneros subastados (o concesionados) y en esa medida sí hay un compromiso del impresor para hacer esos favores. Se habla de manera genérica de "papeles de gobierno", y tenemos algunos datos de cuánto pagaron los impresores para la subasta de otros géneros, no solo los noticiosos. Solamente quiero añadir que en el caso de la Gaceta de literatura de México (1788-1795) de José Antonio Alzate era claramente un negocio a pérdida, pero allí había un proyecto cultural, al menos para este período, de los grupos ilustrados y criollos para hacer un bien a la sociedad, ilustrándola con algunas noticias. Pensar que solo estaban buscando un rédito financiero podría disminuir la apreciación del potencial político de la agenda que tuvieron ciertos impresores. El caso que estudia Suárez se refiere precisamente a la familia Zúñiga y Ontiveros, que tiene un papel muy relevante en la segunda mitad del siglo XVIII y se extiende al XIX.

Paul Firbas: Es una suerte que hayas podido acompañarnos, Marina. Añado brevemente dos cosas: por un lado, el carácter 
excepcional del corpus que venimos estudiando y editando con José Antonio Rodríguez, porque los Diarios de Lima se extienden por doce años (1700-1711) de modo ininterrumpido y con emisiones periódicas bastante regulares (cada dos meses); y que gracias a ese archivo conocemos el ritmo de la imprenta de Lima, no solo por los diarios y noticias que iban tirando, sino por la información que estos contienen sobre otros impresos. Es un archivo excepcional que nos permite seguir a un impresor que opera el único taller en la ciudad. Este caso seguramente tenga alguna semejanza con lo que Javier y Carmen han estudiado sobre la familia Huarte en la ciudad de San Sebastián ${ }^{16}$ o con el mencionado estudio de Camprubí sobre el régimen de monopolio, aunque breve, instaurado por el Archiduque en Barcelona en 1706 para el impresor Figueró. Por otro lado, si pensamos en la ciudad barroca, antes del período ilustrado, conviene entenderla como un espacio cultural multimedia. En ese sentido, pienso que quizá en nuestro siglo XXI estamos mejor equipados para leer el barroco que nuestros colegas ilustrados y modernos. Quiero decir que cuando había una fiesta, una celebración o un acontecimiento importante, la imprenta operaba como parte de una máquina política multimedia. Por eso, habría que incluir a los impresos efímeros - noticias, carteles, relaciones, bandos-, como parte de esa política barroca que se representaba en la ciudad y se extendía a los pueblos. ${ }^{17}$

José Antonio Rodríguez Garrido: Sobre la relevancia de estudiar estos textos como parte de una producción económica, aceptando su importancia, lo que quisiera hacer notar es que, en los Diarios de Lima que editamos, se hace muy visible la construcción de un lector a lo largo de esos doce ańos de producción. Hay una permanente referencia a la gran ex-

16 Ver Javier Díaz-Noci y Carmen Espejo Cala (2017)

17 Sobre "edictos, carteles y pasquines" en las ciudades hispánicas de la temprana Edad Moderna, ver Antonio Castillo Gómez (2019). 
Las noticias impresas en la Monarquía Hispánica (siglos XVI-XVIII): nuevos estudios y métodos

pectativa por la avidez de información, ante la ausencia o ante la llegada de las noticias, que va siendo tematizada constantemente a lo largo del texto, y en los pasajes retóricamente más atractivos el redactor recurre a una oralidad para crear una simulación de comunicación directa con el receptor. Si bien para considerar adecuadamente la recepción y circulación de noticias resulta central preguntarse sobre el soporte económico del proyecto -y la idea, que acaba de presentar Marina, de que esto formaba parte de un bloque de papeles más o menos oficiales, da una buena respuesta a esa pregunta- creo que también merece atenderse a la construcción del posible lector en los textos de estas noticias, un asunto que está por estudiar. Se trata, a mi parecer, de un texto que no está pensado sólo para un público reducido o cercano al contexto oficial, y en tal medida podemos imaginar también a un público que accedería a través de la lectura en voz alta (como sabemos, uno de los medios habituales de difusión de los textos escritos: el que sabía leer leía para varios). De este modo, podemos pensar en un campo de recepción más amplio, que podríamos estudiar como el de la creación de un público consumidor de noticias. El hecho de que el Diario de noticias sobresalientes en Lima se publique a lo largo de doce años y de que haya sido precedido por impresos sueltos de noticias durante el siglo XVII puede leerse también como la formación de un público de este tipo de textos. Esa continuidad va creando un hábito y una expectativa de lectura, que yo creo es algo por estudiar.

Javier Díaz-Noci: Las noticias y los impresos se vendían, ciertamente, al menos en España, y esto incluye sus mercados informativos en Italia y Ámsterdam. Las hojas de noticias, las publicaciones periódicas y otros pliegos menores complementaban los ingresos de los impresores, sobre todo en el caso de aquellos que tenían que competir con los colegas que recibían los encargos oficiales de las instituciones civiles y religiosas. Por otra parte, el editor y el impresor a 
veces se funden en una misma persona, pero no siempre: recordemos el caso de Francisco Fabro Bermudán (quien puso en marcha en Madrid la Gaceta Nueva en 1661), que muchas veces no solo recoge noticias sino que reimprime las de otros. Incluso en ocasiones reimprime series enteras; otras veces, números sueltos de gacetas. ${ }^{18}$

Paul Firbas: Para finalizar este bloque, leo uno de los comentarios del chat. Judith Farré, colega que estudia la corte virreinal mexicana, nos manda un comentario a propósito de la intervención de José Antonio sobre la creación de un público lector desde los textos de noticias, dice: "La construcción del lector en este circuito informativo y las apelaciones a la oralidad se pueden contraponer a las alusiones a la vista, que son fundamentales en las relaciones de fiestas. Estaríamos en un oír frente a un ver”.

\section{Filología, ediciones de textos noticiosos y humanida- des digitales}

Paul Firbas: Vamos a conversar en este bloque sobre el trabajo, en el que creo que todos nosotros andamos más o menos involucrados, de producción de ediciones críticas pero con nuevas herramientas digitales y plataformas en línea. No sé si te apetece comenzar, Francisco (Paco), y comentarnos un poco sobre tu propio proyecto, que, si no me equivoco, guarda relación con los grabados incluidos en estos impresos y las herramientas digitales.

Francisco Baena: Este es un trabajo que hemos realizado la profesora Carmen Espejo y yo en los dos últimos ańos, que está prácticamente en imprenta y se publicará en los próximos meses. Es un trabajo que se titula "Ilustraciones de portada y poderes políticos en el periodismo español de la Edad

18 Ver Javier Díaz-Noci (2021, pp. 53-57). 
Las noticias impresas en la Monarquía Hispánica (siglos XVI-XVIII): nuevos estudios y métodos

Moderna”. ${ }^{19}$ En él hemos analizado las representaciones de los poderes políticos a través de los grabados, de las imágenes que ilustran las portadas de los impresos informativos de la Edad Moderna: relaciones de sucesos, en mayor medida, gacetas, etc. Hemos trabajado con un corpus de 162 relaciones de sucesos y gacetas publicadas en Sevilla entre 1618 y 1635. Una primera aproximación cuantitativa nos ha permitido medir la presencia de la imagen en portada, así como proceder a una clasificación de estas imágenes en función del contenido o de su finalidad editorial, además hemos llegado a la conclusión de que la presencia de estos elementos iconográficos fue menos importante de lo que la bibliografía afirma habitualmente, incluso en los géneros de contenido más sensacionalista. En la gran mayoría de los casos analizados, la ilustración no se usa para hacer referencia de manera directa al evento narrado, sino que se suele utilizar más bien para enfatizar el género del impreso. Por ejemplo, los grabados que hemos extraído de veinte relaciones del impresor sevillano Juan de Cabrera, que servían para ilustrar noticias sobre batallas y gestas militares. Es decir, más que hacer referencia de manera directa a la noticia, lo hacen a la temática. También hemos detectado que casi la mitad de los impresos del corpus cuenta con un grabado en portada que reproduce un escudo de armas. Es muy habitual que la imagen que ilustre los impresos informativos sea un escudo de armas: en el caso que vemos, asociado a la Casa de Austria, al poder monárquico, en distintas versiones. Esta observación nos permite afirmar que el periodismo espańol experimenta una creciente oficialización mucho antes incluso de la aparición del primer periódico oficial del rey. Treinta o cuarenta ańos antes de la aparición de la Gaceta Nueva, ya se publican relaciones y gacetas con el marchamo de oficialidad, símbolo de

19 El artículo fue publicado en inglés. Ver Carmen Espejo Cala y Francisco Baena (2021). 
esa vinculación explícita o implícita con el poder político. Y, para terminar, el estudio de un pequeño grupo de impresos, en cuyas portadas aparecen escudos de armas eclesiásticos o nobiliarios, nos ha llevado a considerar estas imágenes como un indicio del interés que tenían los poderes locales en el florecimiento del mercado periodístico de la Edad Moderna. Por ejemplo, el Conde de Roca, diplomático español, que trabajó en Italia y publicó un tratado de diplomacia muy importante (en él, precisamente, daba instrucciones de cómo redactar los avisos), cuyo escudo nobiliario encontramos en dos relaciones de Juan de Cabrera. Esto es lo que puedo trasladar de esta reciente investigación.

Paul Firbas: Es un trabajo notable y de enorme utilidad. Me parece interesantísima esa nueva cronología que planteas en relación con la oficialidad a partir de las imágenes grabadas en las relaciones de sucesos.

Tadeo Valverde Molina: Ya que se ha hablado de relaciones de sucesos y de ilustraciones, cuando avanzaba en la edición de una comedia me encontré con dos relaciones de sucesos que resultaban vinculantes, entre las dos. Trabajaba en la edición de una comedia suelta, El míralo todo en Castilla, en Nápoles y en Sicilia, una comedia anónima, compuesta por un ingenio sevillano, estudiante del Colegio Mayor de Santa María de Jesús en Sevilla. Esta comedia forma parte de un ciclo de representaciones cortesanas, entre 1729 y 1733 (cuando estuvo la corte en Sevilla) y que se disemina luego de manera impresa desde el taller de Eugenio García Honorato y San Miguel en Salamanca, alrededor de 1733. He cotejado al menos tres ediciones distintas para realizar la edición de esta comedia, y una de ellas está claramente identificada en el taller de Salamanca. Otra parte del ciclo de representaciones también está vinculada a este taller. He encontrado tres testimonios, identificados como B (texto base), M y N, conservados en la British Library, la Biblioteca 
Las noticias impresas en la Monarquía Hispánica (siglos XVI-XVIII): nuevos estudios y métodos

Menéndez Pelayo y la Biblioteca Nazzionale di Napoli, respectivamente. Esta comedia no es exactamente de una gran elevación lírica, pero resulta de interés debido a su mención de hechos importantes para la historia cortesana, como los casamientos de los infantes de España y Portugal en la corte de Lisboa en 1728 y los desposorios en Badajoz en 1729. Al investigar sobre las relaciones de estos hechos me encontré con La relación y verdadero romance de los desposorios en Lisboa (marcada con el escudo de armas de Felipe V), compuesta por Rodrigo Fernández de Soto e impresa en Sevilla por la viuda de Francisco Lorenzo de Hermosilla; y su contraparte -con el mismo título- también desde dos focos del poder, la corte de Lisboa, donde se enfatiza especialmente el viaje del marqués de los Balbases, embajador de Felipe $\mathrm{V}$ e invitado a esta ceremonia de desposorios, impreso en Lisboa Occidental por Miguel Rodrigues; y la Descripción verdadera y puntual noticia, que describe los casamientos en Badajoz, donde se eligen las orillas del río Caya como un espacio concomitante entre España y Portugal para llevar a cabo estas dobles nupcias, impresa en Sevilla por la viuda de Francisco Leefdael. En la comedia, además, son importantes las referencias a la circulación de noticias, específicamente en la jornada segunda, donde se mencionan las "relaciones dudosas" que llegaban desde Portugal a España. Aún me gustaría estrechar más esta triangulación entre relaciones impresas en Sevilla, la comedia representada en el palacio del Real Alcázar de Sevilla y cómo llegan a Salamanca, tema que desarrollé en la edición de El míralo todo, ya prácticamente en prensa. Me parece una manera importante de retroalimentar teatro y prensa.

Paul Firbas: Esa conexión entre teatro y prensa, y entre público espectador y lector en el contexto de la corte y de un mercado de consumidores culturales abre una línea de investigación importante. Quizá no esté de más recordar los trabajos de Roger Chartier, quien tanto provecho ha sacado 
de las escenas teatrales para el estudio material de los textos, su circulación y la historia de la lectura. ${ }^{20}$

Me gustaría invitar a Javier para que nos hablara sobre su trabajo como editor de gacetas, sobre el grupo DigiDoc y los proyectos de documentación digital de la Universidad Pompeu Fabra.

Javier Díaz-Noci: DigiDoc es un grupo de investigación, que ahora coordino hasta 2022, dedicado a la investigación y la documentación digital. La ventaja que tiene son los seminarios DigiDoc, y también una línea editorial muy flexible, que hacemos nosotros, y que se llama DigiDoc Reports. Son lo que llamamos entregables, sobre cuestiones metodológicas. Cuando Carmen descubrió la Gaceta de Roma en la biblioteca de Turín, se dio cuenta de que no se trataba de relaciones de sucesos aisladas sino de una gaceta semiperiódica, situada en esta frontera entre lo ocasional y lo que empieza a ser periódico. En esta edición, online y gratuita, sí que nos hemos planteado una edición filológica, con criterios de edición de prensa antigua en castellano. También tenemos un cuadro para hacerlo en catalán, que es la otra gran lengua española. Solo se publica una editada en lengua vasca y ninguna en gallego. En este libro, la Gaceta de Roma, hacemos una edición filológica y una edición crítica de estas gacetas, así como una transcripción paleográfica (hemos renunciado a la edición facsímil, por varios motivos) y una edición modernizada, que supone algo más que modernizar la ortografía: implica tomar decisiones respecto a préstamos y extranjerismos (italianismos), o respecto a la identificación de topónimos y antropónimos que nos ha dado un trabajo excepcional a Carmen, a mí y sobre todo a Rafael Soto, el encargado de esa parte. Yo he trabajado más en la parte mecánica de la transcripción y la modernización de las gacetas. Todo ello con la esperanza de

20 Ver Roger Chartier (2015) y (2012). 
Las noticias impresas en la Monarquía Hispánica (siglos XVI-XVIII): nuevos estudios y métodos

cumplir un doble objetivo, el primero hacer una edición filológica seria, como se hace de otro tipo de textos, por ejemplo, teatrales y el segundo es el de tener los textos digitales para poder incluirlos en bases de datos para trabajar más cómodamente en el ámbito digital. Por otro lado, en los Quaderns de la Pompeu Fabra hemos publicado textos sobre la imagen del periodista en la Edad Moderna, cuestión que tratamos en las clases que imparto en la universidad; y traducciones al castellano de los avisos burlescos de Bolonia del siglo XVII y una selección de comedias inglesas contemporáneas a Shakespeare que se ocupan del periodismo. ${ }^{21}$

Paul Firbas: Si me permiten, quiero volver sobre un concepto que quedó pendiente. Naturalmente, este no es el lugar para resolverlo, pero sí puede serlo para plantear el problema. Creo que, en general, nos falta entender mejor qué era un pliego suelto, qué es un texto efímero, y seguir pensando en el concepto de libro. En la medida en que ahora tenemos acceso a mucha más información, es importante repensar algunos estudios clásicos, como los de Jaime Moll o Víctor Infantes, sobre los grados de lo efímero. ${ }^{22} \mathrm{Y}$, sobre cuestiones específicas de filología, de ediciones críticas y anotaciones de los textos, quisiera comentar que el trabajo de edición es también una forma de lectura, de lectura profunda y humana, en contraste con la lectura distanciada de los datos y la informática. En el caso de los impresos de Lima, la lectura de noticias a lo largo de doce años compone una historia de la ciudad, revela una narración, un proyecto que se abre y se cierra no solo por las razones de imponen las noticias europeas de la Guerra de Sucesión, sino también por razones internas, del propio proyecto del impresor, me parece. Y metodológicamente, podemos intentar ver cómo esa percepción humana que adquirimos como lectores-editores puede corro-

21 Javier Díaz-Noci (Ed. y trad.) (2021).

22 Ver Jaime Moll (1994) y Víctor Infantes (2003). 
borarse a partir de ciertas herramientas digitales. Por ejemplo, he aplicado un software de acceso libre, AntConc 3.5.8 (Windows), que recomiendo mucho, para hacer y graficar concordancias. Así, la percepción que tenemos del sentido final del conjunto documental puede corroborarse con la visualización de algunas palabras, como fiesta, toros o comedia, o campos semánticos que se intensifican al final de todos los Diarios. Las herramientas digitales pueden apoyar o corroborar nuestras lecturas, pero también pueden abrirnos nuevas posibilidades de entender los textos.

\section{Censura y circulación impresa}

Paul Firbas: Entremos ahora a conversar sobre la censura y circulación de los impresos de noticias. Quiero preguntarle directamente a Pedro Guibovich, que se ha especializado en la censura de libros y la imprenta del virreinato del Perú, ${ }^{23}$ si él veía o entendía que los impresos efímeros o noticiosos se regían por otro tipo de mecanismo de censura, o si era básicamente el mismo que en los libros, pero que no se hacía visible (no hay paratextos) por falta de espacio o tiempo. ¿Cómo ves la diferencia entre el libro y el pliego suelto en relación con la censura?

Pedro Guibovich: Es una muy buena pregunta, pero muy difícil de responder, porque estas relaciones de noticias, como en general muchos impresos salidos de los talleres limeños, no han sido objeto de un estudio sistemático; pero lo que sospecho, a partir, precisamente de la referencia en la portada del Diario de noticias, que dice "Con licencia del superior gobierno", es que debemos asumir que el texto pasó por un revisor. Lo que sí pude determinar a partir de la lectura de los preliminares de algunos libros, es que el propio virrey intervino alguna vez para eximir de examen a un sermón de

23 Ver Pedro Guibovich (2013 y 2019). 
Las noticias impresas en la Monarquía Hispánica (siglos XVI-XVIII): nuevos estudios y métodos

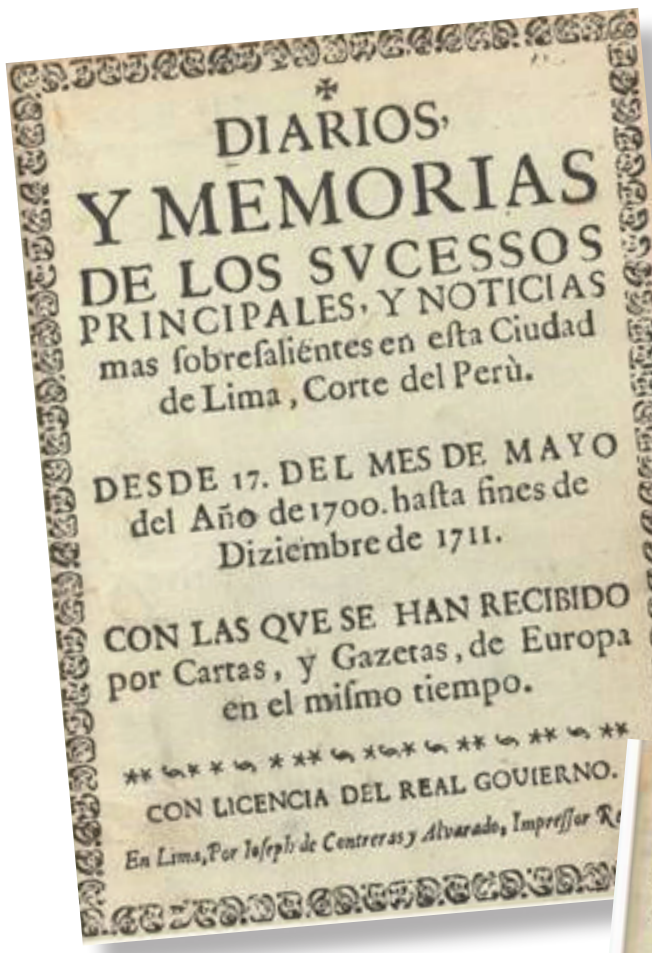

Figura 2. Portada facticia del volumen que reúne más de cien impresos sueltos noticiosos de la imprenta limeña de Joseph de Contreras y Alvarado publicados entre 1700 y 1711; y primera página del primer Diario de noticias sobresalientes en Lima (abril a mayo de 1700), incluido en el volumen. Estos impresos noticiosos han sido editados recientemente por Firbas y Rodríguez Garrido (2017 y en prensa) [New York Public Library]

deftr 17 dalmesdo MagOS SOBRESALIENTES

y continuart Ma g o tufta la parrida de efte Correoi Correos el toparle en adclanterodoslos prellor de ella Ciudzat. saro.

(1) Maro.

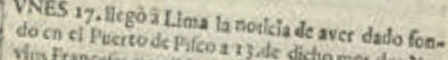

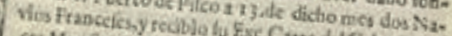

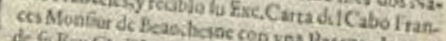

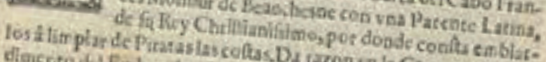

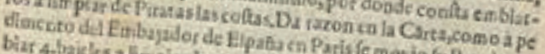

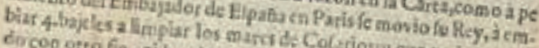

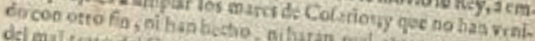

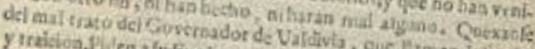

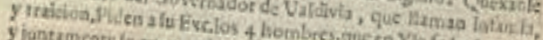

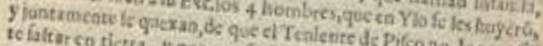

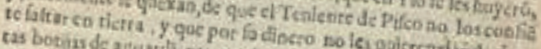

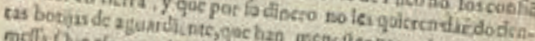

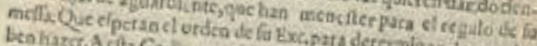

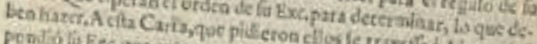

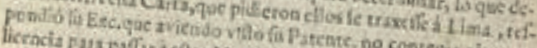

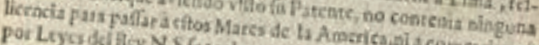

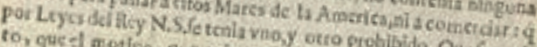

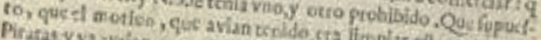

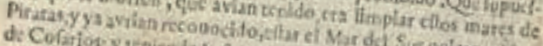

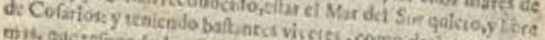

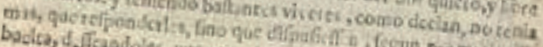

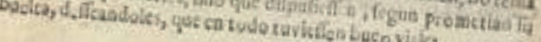


principios del siglo XVII. Y ello porque el virrey consideró que la fama y el crédito del predicador hacían que la censura fuera innecesaria. En todos los textos que he revisado, consta que pasaron, salvo este, por la censura. Es decir, muy probablemente aquellos pliegos, trátese de hojas volantes, relaciones de noticias, entre otros, también pasaron por la mirada del censor. Pienso que el tiraje de estos pliegos, que circulaban, seguramente fue importante, quizás de uno, dos o tres centenares. En consecuencia, era necesario ejercer un tipo de control sobre esa información que podía alcanzar regiones distantes de la capital. La historia de la imprenta en el Perú, en particular de la producción y de la censura, es un campo poco explorado. ${ }^{24}$ En cuanto a la circulación de noticias, hay una excepcional fuente que se publicó hace unos años: la correspondencia de Francisco Javier de Luna Pizarro, un clérigo muy próximo al poder colonial, con su cuñado Felipe Antonio de la Torre y Campos, residente en el valle de Majes, entre 1813 y $1821 .{ }^{25}$ ¿Cuál es el interés de este epistolario? En sus cartas, Luna Pizarro da cuenta detallada de la información de Europa u otras partes de América que se recibe en Lima por medio de diarios de noticias, boletines, gacetas, y, que por orden del virrey, es seleccionada y publicada. Entonces, en parte, respondiendo a la pregunta sobre la circulación de los textos, ¿qué es lo que hacía Luna Pizarro? Enviaba impresos o noticias, usualmente extractos de ellas tomadas de las gacetas, a su pariente. Y volviendo al tema de la censura, creo que estuvo presente en la producción de la mayoría de los textos.

24 Para la historia de la imprenta en el Perú durante el período colonial, siguen siendo imprescindibles los catálogos y estudios de Medina (1904), Romero (1940) y Vargas Ugarte (1953-1956). Para un estudio reciente sobre la poca frecuencia de noticias americanas en los impresos noticiosos europeos a causa de la censura, ver Espejo-Cala (2019).

25 Ver el libro de Javier de Belaúnde (2006). 
Las noticias impresas en la Monarquía Hispánica (siglos XVI-XVIII): nuevos estudios y métodos

Paul Firbas: Venimos trabajando con muchas reimpresiones en Lima de gacetas, sobre todo de la Gaceta de Madrid, y hemos observado que en la mayoría de los casos se trata de reimpresiones literales. Sin embargo, hay algunos ejemplos fascinantes en los que los editores en Lima agregan y matizan las noticias a partir de otras informaciones y fuentes que las completan. $Y$ en esos casos es interesante imaginarse cómo habrían funcionado las instancias de censura, supongo que cotejando el original con la reimpresión y validando o censurando cualquier diferencia. No sé si José Antonio quiere agregar algo en este sentido, ya que nos hemos encontrado con varios pasajes de agregados limeños en la reimpresión de noticias europeas.

José Antonio Rodríguez Garrido: Sí, justamente, quería comentar sobre eso. Pero antes quería añadir algo sobre las licencias para la publicación de los textos noticiosos. Yo creo que en algunos casos la licencia estaba implícita porque el impreso ya venía autorizado e incluso ordenado por el propio virrey. En los últimos números del Diario de noticias sobresalientes en Lima, ya en 1711, recuerdo específicamente la mención a que el virrey ha querido que se difunda este impreso, que trata precisamente de la presencia de Felipe V en un contexto particular durante la Guerra de Sucesión que permite organizar una celebración del Corpus en un pueblo, con la presencia del propio monarca. Es un asunto muy relevante para el virrey-obispo, Diego Ladrón de Guevara, en ese momento, pues realza su propia posición de virrey y dignidad eclesiástica en Lima, y se nota claramente que hay un interés personal del propio virrey en difundir esa noticia. Esto delata en parte cómo podía ser el procedimiento: la impresión viene autorizada e incluso avalada de antemano por la autoridad. Me referiré ahora al nuevo tema que planteabas, Paul: el de la reescritura de noticias recibidas o la existencia de lo que podríamos llamar un "taller editorial de noticias". Creo que en los primeros años del Diario, el procedimiento es mucho más mecánico. Es decir, se reciben los impresos eu- 
ropeos y sencillamente se reproducen; pero conforme pasan los ańos, el trabajo se vuelve más complejo. Hay un impreso limeño que se titula Diario general de todo lo sucedido en Espana desde que salieron las dos armadas de galeones y flota de estos reinos para los de América y es particularmente atractivo para observar las intervenciones. Se trata de un impreso, de 1706, particularmente extenso dentro del grupo de textos efímeros. Es significativo que el título, Diario general, remite a un impreso sevillano de ese mismo año, que es reproducido casi en su totalidad, pero se suprimen las catorce primeras páginas del texto original. Conectando este tema con el que planteaba Carmen al principio de la reunión, sobre el estudio de casos y la microhistoria de la circulación de noticias, yo creo que este es un caso que ameritaría un enfoque de esa naturaleza, porque el impreso sevillano original estaba pensado para su difusión en América. Justamente una de las partes que sustituye el impreso limeño es la declaración de la causa de imprimir el papel que llevaba el impreso sevillano. Allí claramente se explicaba que el objetivo de aquel impreso era que con él "la muy leal ciudad de Sevilla" mostraba su fidelidad hacia el Rey, como ejemplo para las ciudades de América; ${ }^{26}$ pero cuando se reproduce el impreso en Lima, se suprime esta parte introductoria y, de otro lado, en el cuerpo de la noticia, donde se relatan los avances y sucesos de la Guerra de Sucesión, se combina la relación sevillana con dos fuentes más, una de las cuales he podido identificar y que, en principio, parecería alejada del corpus de noticias: la biografía de una monja granadina, que predijo la muerte del rey Carlos II y la llegada al trono de un príncipe francés. De este modo, a las noticias del impreso sevillano, se le ańade este aval místico

26 El impreso limeño que reproduce parcialmente este Diario general sevillano puede consultarse en facsímil, junto con los demás Diarios y Noticias de Europa, en la página web: https://sites.google.com/view/ diariolima1700, editado modernamente como Noticias de Europa 17 (Firbas y Rodríguez Garrido, eds., 2021, en prensa). 
Las noticias impresas en la Monarquía Hispánica (siglos XVI-XVIII): nuevos estudios y métodos

y religioso de las predicciones de esta monja. Creo que casos como este revelan que hubo un verdadero taller o un editor con propósitos y capacidad para reestructurar y resignificar las fuentes recibidas.

Paul Firbas: Además, la Guerra de Sucesión afectó el flujo regular de los cajones de avisos, es decir, de la fuente oficial de noticias. Hay mucha interrupción en la comunicación transatlántica por canales oficiales. Entonces, empiezan a abrirse otras rutas y otras fuentes. Buenos Aires se convierte en una ruta posible y, desde allí, por la vía austral los barcos arriban al Callao. También algunas noticias van por tierra, a través de Charcas. Es notable que, por ejemplo en 1709, en el puerto limeńo haya tres o cuatros barcos franceses anclados, y con ellos noticias de diversas fuentes y lenguas. Los Diarios narran cómo van llegando las noticias, cómo se va evaluando su fiabilidad, e inclusive en algunos casos se dan detalles sobre cómo se seleccionan. Allí hay un taller editorial que merece estudio.

Carmen Espejo: Si me permites, quisiera agregar, primero, que me está pareciendo fascinante todo lo que estáis comentando. Me hace volver a retomar una idea que también me ha servido últimamente. Hay un historiador italiano, Domenico Cecere $^{27}$, de quién recientemente he leído un trabajo en el que sostiene que, a diferencia de otros imperios anteriores y posteriores, en los que se intentaba irradiar desde el centro a la periferia, hay historiadores que parecen haber definido

390 con acierto el imperio de los Austrias como un imperio policéntrico. Por este motivo, el autor afirma que deberíamos empezar a pensar las redes de comunicación desde esa misma perspectiva, y que quizás, aunque como yo decía al principio, hemos asumido el concepto de redes de noticias desde el centro a la periferia. Hemos prestado poca atención, dice Cecere,

27 Domenico Cecere (2019). 
a las conexiones de los nodos de las redes que no pasan por el centro, que comunican una periferia con otra. El artículo que he leído de este historiador trataba sobre una serie de impresos limeños sobre unos terremotos ocurridos a finales del siglo XVII, que llegaron al parecer directamente a Nápoles y luego a otras localidades españolas ajenas, digamos, al circuito principal, por ejemplo a Salamanca, recordé escuchando a Tadeo, y me pareció muy interesante, la tridimensionalidad de las redes, pero no necesariamente desde el centro a la periferia, sino a través de esa "capilaridad", por así decirlo, un poco retomando la idea de Paul, podríamos aprender mucho de los estudios neuronales para pensar cómo funciona esa red, de cómo se ponen en contacto nodos que no necesariamente pasan por el centro. Eso me parece fundamental. Y un poco retomando también lo que se ha planteado en varias intervenciones, creo que por el mismo determinismo que nos hace pensar el pasado desde la dimensión del poder, pensamos la Edad Moderna desde el poder monárquico, pues prestamos mucha más atención -desde el contexto de las redes de noticias o de la publicación de los impresos- a aquellos que provienen de los intereses de la geopolítica monárquica que a los micropoderes que también tenían interés en utilizar la imprenta para hacer llegar su perspectiva política. En ese sentido, Paco (Francisco Baena) y yo, en nuestro artículo sobre los escudos, al final, después de ver en los impresos el escudo oficial de la casa de los Austrias, en realidad, lo que más nos ha aportado han sido los textos en los que el escudo no es el monárquico, sino el de un noble. Eso nos hace pensar que, además de la gente convencional, el rey o virrey, que quieren que se sepa algo, también hay muchos otros agentes con necesidades comunicativas que utilizan la imprenta. De ahí un poco la idea que al principio quería transmitir sobre la necesidad de hacer microhistoria porque, precisamente, la red lleva la información desde un punto alejado a otro punto alejado, pero una vez que llega a la localidad donde se va a imprimir la noticia, podemos imaginar que se expande 
Las noticias impresas en la Monarquía Hispánica (siglos XVI-XVIII): nuevos estudios y métodos

en varias direcciones. Allí son varios los que la utilizan para diferentes fines. Justamente, esa densidad de saber para qué se utilizaban las noticias es lo que le interesaba a Filippo de Vivo y también a mí. Puede ser una aproximación interesante para nosotros.

Paul Firbas: Me parece muy productiva esa idea de los centros múltiples. En Sudamérica, sin duda Lima era el centro de producción y diseminación de noticias. Desde hace mucho, con los cambios que se han producido en nuestra disciplina, la dicotomía centro-periferia, aunque útil, nos resulta insuficiente. Además, tenemos las contribuciones de tu propio trabajo, Carmen, sobre los puertos que fueron la vanguardia peninsular en la producción de noticias, adelantándose a Madrid.

\section{Proyectos y comentarios finales}

Paul Firbas: Entrando en este último bloque, que es sobre proyectos y comentarios finales, yo querría decir que, siguiendo sugerencias de Carmen, en mi estudio del movimiento de las noticias transatlánticas, me parece cada vez más relevante el problema de la distancia, de ver cómo esa es una variable que está siempre presente, aunque los impresos a veces parecen negarla. La distancia no solo incide en el tiempo de la circulación de noticias, sino que afecta su carácter. Me pregunto, siguiendo algunas ideas de Chartier, ¿hasta qué punto la función de la imprenta colonial era crear presencia

392 de ese mundo metropolitano ausente y distante? ¿Y cómo se produce esa presencia con las noticias impresas? La demanda de presencia podía ser mucho más acuciosa desde las enormes distancias de las ciudades virreinales. Las imprentas en ciudades como Lima, México, Guatemala o Puebla estaban cumpliendo las mismas funciones que en España, pero con un peso simbólico adicional que consistía en producir presencia a través de la letra de molde, cuya función primordial 
EN EG GOVIERYCODEL EXCELENIISII.

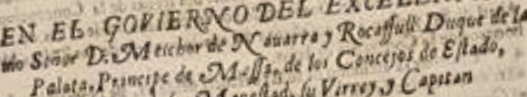

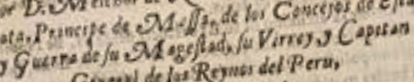

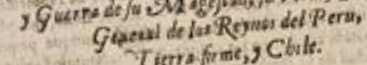

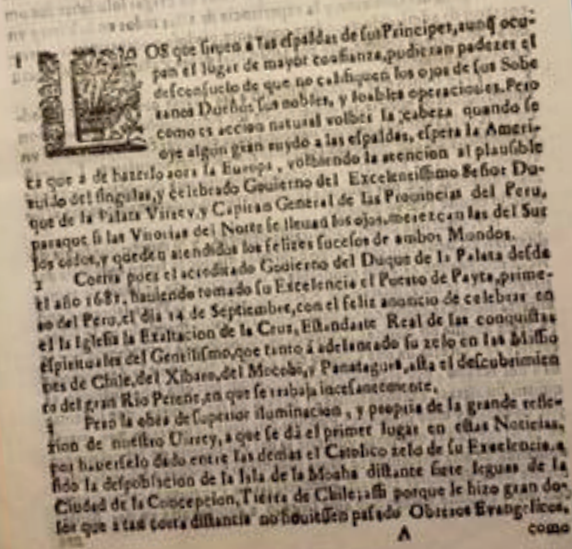

NOTICIAS del Norte, Italia, y ERpaña,publicadas Jueves t. de Sericmbre de 1089 .

$$
\text { Vappoisertapioliod i689. }
$$

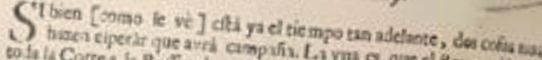

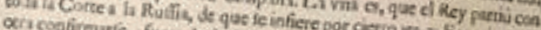

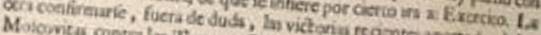

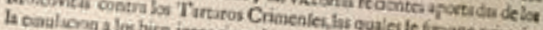

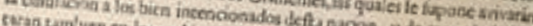

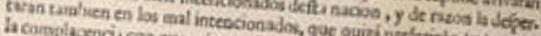

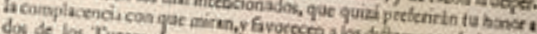

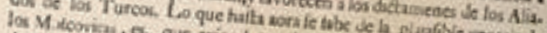

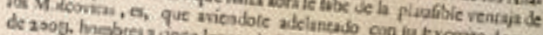

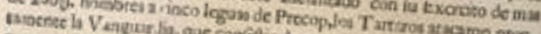

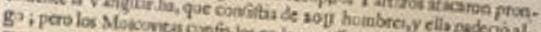

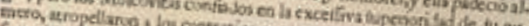

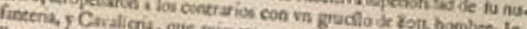

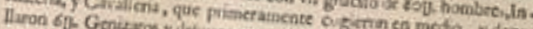

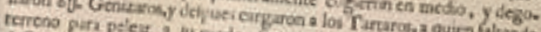

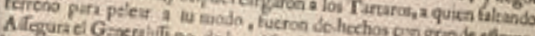

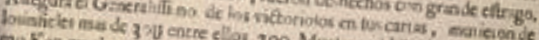

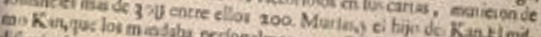

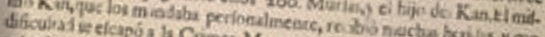

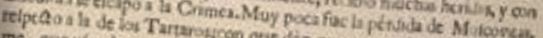

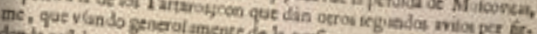

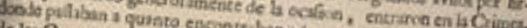

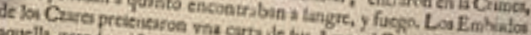

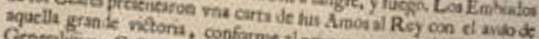

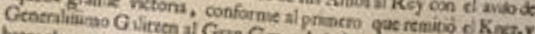
hazer alge contra lov Tien Gran Geveril defti Corons, alcnundoles nar focotro \&e lox de ta Crimes. Bubtic, que ya bos tienen q.e elpe. Vind a Crimes.

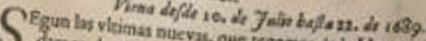

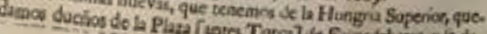

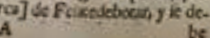

Figura 3. Imagen de la izquierda: primera página de uno de los raros ejemplares de las Noticias del Sur (sin pie de imprenta), probable serie de periodicidad variable publicada en Lima por Joseph de Contreras de Alvarado entre 1686 y 1688 [New York Public Library]. Aunque la estructura narrativa corresponde más a una relación de suceso que a una gaceta, las Noticias del Sur conectaban el gobierno virreinal peruano con las noticias europeas. Imagen de la derecha: primera página de las Noticias ordinarias del Norte, Italia y España, publicada en Sevilla por Tomás López de Haro en 1689 [Fondos de la Universidad de Sevilla]. Una gaceta similar, pero de Noticias extraordinarias del Norte se publicaba en el mismo año en San Sebastián, en la imprenta de Pedro de Huarte. 
Las noticias impresas en la Monarquía Hispánica (siglos XVI-XVIII): nuevos estudios y métodos

es la de fijar sentidos. Yo creo que ahí también hay un campo posible que puede abrirse a la investigación, inclusive a una investigación de cuestiones más literarias, tomando en cuenta esa dimensión narrativa que tiene el impreso, sobre todo cuando empezamos a leer una serie periódica en secuencia y a construir, como lectores, algo así como la historia de una ciudad y sus redes.

Javier Díaz-Noci: Es cierto que son temas muy interesantes, tanto el de la temporalidad como el de la periodicidad. El concepto de periodicidad no es igual ahora en tiempos de internet, que es inmediatez absoluta y globalización, que en el siglo XVII, o en tiempos bélicos o prebélicos, cuando los flujos de información y la posibilidad de transmitir, recibir o proveerse información dependía de muchos factores. Esto se ve muy bien con el análisis social de redes, que es lo que practicamos en la edición de la Gaceta de Roma, y también en un artículo sobre la gaceta de Ámsterdam, que publicó un judío sefardí de origen portugués en castellano, junto con gacetas en jiddish o en italiano. ${ }^{28}$ Manejaba varias lenguas para obtener algo de dinero. Es la dependencia de determinados agentes, fuentes, núcleos o sociedades informativas, que despuntan muy claramente. Roma, por ejemplo, Venecia, donde la presencia de judíos es también muy importante, Hamburgo, es otro de estos lugares, Ámsterdam, por supuesto, Londres y París. Aquí se ve un poco hasta qué punto la Península Ibérica es un lugar periférico, ya que en todas estas publicaciones la información que llega de Espańa o Portugal es un poco de segunda mano, al igual que la que llega de Suecia, de Dinamarca, de Varsovia o de Moscú, que son lugares más alejados. También hemos notado cuando hemos editado estas gacetas vascas o la Gaceta de Roma-en el caso de las vascas que reimprimen una gaceta en castellano de Flandes- que

28 Javier Díaz-Noci (2020). 
por motivos probablemente de censura y de actualidad, se suprimen las noticias de Espańa, porque son de ida y vuelta. Es decir, van de Espańa a Bruselas, con quince días de retraso se imprimen, se consumen a la semana, llegan en quince días, y tardan una semana en reimprimirse. Claro, ha pasado un mes y medio, y esa actualidad o esa frescura se pierde. En el caso de las informaciones que vienen de o van a América, yo creo que se abre un campo muy interesante, no solamente con la América de habla española sino con la de habla portuguesa. Recordemos que, en Brasil, la imprenta está prohibida hasta que llega la familia real portuguesa y se establece en Río de Janeiro, la capital del imperio en sustitución de Lisboa cuando Napoleón entra en Portugal, efectivamente, a principios del XIX. Mientras tanto viven de importaciones, de oralidad y de otro tipo de géneros igualmente muy interesantes.

Paul Firbas: Nos quedan, felizmente, muchos temas pendientes para futuras reuniones. Esperemos que este formato nos haya servido para mantener un diálogo abierto, sin los compromisos de una ponencia. Les agradezco muchísimo su participación.

Recibido: 20 de agosto del 2021

Aprobado: 15 de setiembre del 2021

\section{Referencias bibliográficas}

Baena Sánchez, Francisco y Espejo Cala, Carmen.

(2017) En busca de un vocabulario compartido para describir y representar el periodismo de la Edad Moderna. En Giovanni Ciapelli y Valentina Nider (Eds.), La invención de las noticias. Las relaciones de sucesos entre la literatura y la información (siglos XVI-XVIII) (pp. 108-130). Trento: Università degli Studi di Trento, Dipartimento di Lettere e Filosofia. Recuperado de: https://idus.us.es/handle/11441/74203 
Las noticias impresas en la Monarquía Hispánica (siglos XVI-XVIII): nuevos estudios y métodos

Belaúnde, Javier de

(2006) Justicia sin crueldad. Cartas inéditas (1813-1854) de Francisco Javier de Luna Pizarro, fundador de la República. Lima: Fondo Editorial del Congreso del Perú.

Camprubí, Xevi

(2018) L'impressor Rafael Figueró (1642-1726) i la premsa a la Catalunya del seu temps. Barcelona: Fundació Noguera (Estudis, 75).

Castillo Gómez, Antonio

(2019) Edictos, carteles y pasquines. Papeles efímeros y comunicación urbana en la sociedad hispana de la temprana Edad Moderna. La Bibliofilía. Rivista di storia del libro e di bibliografia CXXI: 207-236. Recuperado de: https://ebuah.uah.es/xmlui/handle/10017/42542

Cecere, Domenico

(2019) Subterranea conspiración. Terremoti, comunicazione e politica nella monarchia di Carlo II. Studi storici: rivista trimestrale dell'Istituto Gramsci, 60 (4): 811-843.

Chartier, Roger

(2015) La obra, el taller y el escenario. Tres estudios de movilidad textual. Almería: Editorial Confluencias.

Chartier, Roger

396

(2012) Introducción. Barroco y Comunicación. En Roger Chartier y Carmen Espejo (Eds.), La aparición del periodismo en Europa (pp. 15-32). Madrid: Marcial Pons.

Croce, Giulio Cesare y Díaz-Noci, Javier (Trad.)

(2021) Avisos burlescos (1627-1638). Barcelona: Pompeu Fabra University, serie Quaderns: Historia del Periodismo y de la Comunicación. Recuperado de: https:// repositori.upf.edu/handle/10230/46340 
Díaz-Noci, Javier

(2021) El oficio de periodista a través de la historia. Barcelona: DigiDoc Research Group (Pompeu Fabra University), DigiDoc Reports. Recuperado de: https://repositori.upf.edu/handle/10230/46350

Díaz-Noci, Javier (Ed. y trad.)

(2021)

El comercio de noticias y otras obras inglesas sobre periodismo (siglo XVII). Selección de obras de Ben Jonson, James Shirley, John Fletcher y Richard Braithwaite. Barcelona: Pompeu Fabra University, serie Quaderns: Historia del Periodismo y de la Comunicación. Recuperado de: https://repositori.upf.edu/ handle/10230/46341

Díaz-Noci, Javier

(2020) Gazeta de Ámsterdam: History and content analysis (1939-2017). Historia y comunicación social 25 (1): 67-78.

Díaz-Noci, Javier; Espejo Cala, Carmen; Baena Sánchez, Francisco (2018) Redes y empresas informativas en España: conexiones de impresores y editores de prensa en el siglo XVII. Barcelona Quaderns d'Historia, 25: 75-85.

Díaz-Noci, Javier; Espejo Cala, Carmen y Baena Sánchez, Francisco (2017) News from the Border: San Sebastian as an information hub in Early Modern Europe. Mediatika 16: 5172. Recuperado de: https://repositori.upf.edu/bitstream/handle/10230/35980/DiazNoci_med_news. pdf

Espejo-Cala, Carmen

(2019) No News from America in Spanish Gazettes: Censorship and News Networks Dependency in Early Modern Spanish Journalism. En Nicholas Brownlees (Ed.), The Language of Discovery, Exploration and Settlement (pp. 25-37). Newcastle upon Tyne: Cambridge Scholars Publishing. 
Las noticias impresas en la Monarquía Hispánica (siglos XVI-XVIII): nuevos estudios y métodos

Espejo Cala, Carmen

(2012) Un marco de interpretación para el periodismo europeo en la primera edad moderna. En Roger Chartier y Carmen Espejo (Eds.), La aparición del periodismo en Europa (pp. 103-126). Madrid: Marcial Pons.

Espejo-Cala, Carmen y Baena Sánchez, Francisco.

(2021) Front-page illustrations and political powers in Early Modern Spanish journalism. Culture \& History Digital Journal 10 (1): e012. Recuperado de: https://doi. org/10.3989/chdj.2021.012

Firbas, Paul

(2021) Facsímiles del Diario de noticias sobresalientes en Lima y Noticias de Europa (1700-1711). Recuperado en: https://sites.google.com/view/diariolima1700/ facsímiles

Firbas, Paul y Rodríguez Garrido, José A.

(2017) El Diario de noticias sobresalientes en Lima y las Noticias de Europa (1700-1711) en su contexto histórico y editorial. En Paul Firbas y José A. Rodrílguez Garrido (Eds.), Diario de noticias sobresalientes en Lima y Noticias de Europa (1700-1711), volumen 1 (17001705) (pp. 9-46). New York: IDEA. Recuperado de: https://dadun.unav.edu/handle/10171/43271

Firbas, Paul y Rodríguez Garrido, José Antonio (Eds.)

(2021) Diario de noticias sobresalientes en Lima y Noticias de Europa (1700-1711), volumen 2 (1706-1711). (en prensa)

Firbas, Paul y Rodríguez Garrido, José Antonio (Eds.)

(2017)

Diario de noticias sobresalientes en Lima y Noticias de Europa (1700-1711), volumen 1 (1700-1705). New York: IDEA. Recuperado de: https://dadun.unav. edu/handle/10171/43271. 
Guibovich Pérez, Pedro

(2019) Imprimir en Lima durante la colonia. Historia y documentos 1584-1750. Madrid y Frankfurt: Iberoamericana/Vervuert.

Guibovich Pérez, Pedro

(2013) Lecturas prohibidas. La censura inquisitorial en el Perú tardío colonial. Lima: Fondo editorial de la Pontificia Universidad Católica del Perú.

Infantes, Víctor

(2003) Los impresos efímeros: búsqueda, identificación y descripción. En Comercio y tasación del libro antiguo: análisis, identificación y descripción (textos y materiales) (pp. 133-199). Zaragoza: Prensa Universitaria.

Medina, José Toribio

(1904) La imprenta en Lima. Tomo I. Santiago de Chile.

Moll, Jaime

Los surtidos de romances, coplas e historias y otros papeles. En De la imprenta al lector. Estudios sobre el libro español de los siglos XVI al XVIII (pp. 45-55). Madrid: Arco/Libros.

Romero, Carlos

(1940) Los orígenes del periodismo en el Perú. De la relación al diario: 1594 a 1790. Lima: Librería e Imprenta Gil.

Soto Escobar, Rafael; Díaz-Noci, Javier y Espejo Cala, Carmen (2020) Gaceta de Roma (Valencia, Felipe Mey, 1618-1620). Estudio y edición crítica del primer periódico español. A Coruña: Sielae. [Janus, Anexos 17] Recuperado de: https://www.janusdigital.es/anexo.htm?id=22

Suárez Rivera, Manuel

(2015) El periodismo en construcción. Estrategias comerciales de la Gazeta de México. 1784-1785. Relaciones 143: 207-231. Recuperado de: https://www.redalyc. org/pdf/137/13741199008.pdf 
Vargas Ugarte, Rubén

1953-1956. Impresos peruanos. Biblioteca Peruana tomos VII-IX. Lima.

Vivo, Filippo de

(2019) Microhistory of Long-Distance Information: Space, Movement and Agency in the Early Modern News. Past and Present, Supplement 14:179-200. Recuperado de: https://academic.oup.com/past/article/242/ Supplement_14/179/5637705

Weststeijn, Arthur

(2021) Empire in Fragments: Transatlantic News and Print Media in the Iberian World, ca. 1600-400. Renaissance Quarterly 74: 528-70. 